\title{
Analisis Teknik Marker Based Tracking Sebagai Media Pengenalan Rumah Adat di Indonesia Berbasis Augmented Reality
}

\author{
Ibnu Hadi Purwanto ${ }^{1}$, Zainal Makhasin ${ }^{2}$, Saefudin Irsyad ${ }^{3}$, Faizal Zulfi Ardiyanto ${ }^{4}$ \\ Email : ibnu@amikom.ac.id ${ }^{1}$, zainal.makhasin@students.amikom.ac.id ${ }^{2}$, \\ saefudin.irsyad@students.amikom.ac.id ${ }^{3}$, faizal.ardiyanto@students.amikom.ac.id ${ }^{4}$ \\ Fakultas Ilmu Komputer, Universitas AMIKOM Yogyakarta ${ }^{1,2,3,4}$
}

\begin{abstract}
Abstrak
Augmented Reality diimplementasikan untuk pengenalan rumah adat yang terdapat di Indonesia sebagai sarana edukasi. Pada Augmented Reality, pengguna (dalam hal ini anak) dapat merasakan sensasi penggabungan objek nyata dengan objek virtual baik secara 2 dimensi maupun 3 dimensi. Dalam menggunakan Augmented reality dapat dilakukan dengan dua metode, salah satunya Marker based tracking. Namun berapa jarak yang optimal untuk digunakan dan berapa sudut kemiringan yang dapat digunakan masih menjadi pertanyaan. Dalam menguji jarak dibutuhkan alat ukur jarak, misalnya penggaris ataupun meteran. Sedangkan dalam menguji sudut kemiringan pendeteksian dibutuhkan alat seperti busur derajat. Pengujian jarak yang dilakukan yaitu dengan variabel $6 \mathrm{~cm}, 12 \mathrm{~cm}, 18 \mathrm{~cm}, 25 \mathrm{~cm}, 35 \mathrm{~cm}, 45 \mathrm{~cm}, 55 \mathrm{~cm}, 65$ $\mathrm{cm}, 75 \mathrm{~cm}, 85 \mathrm{~cm}, 95 \mathrm{~cm}$ dan $100 \mathrm{~cm}$. Sedangkan untuk sudut kemiringannya dilakukan dengan variabel 10o, 20o, 30o, 45o, 60o, 90o, 100o, 110o, 120o, 135o, 160o, dan 170o. Sehingga ditemukan jarak dan sudut yang optimal dalam pendeteksian marker. Kesimpulan yang didapat dari pengujian ini adalah ditemukannya jarak pendeteksian marker minimal yaitu $6 \mathrm{~cm}$ dan jarak maksimal pendeteksian adalah $85 \mathrm{~cm}$ dengan marker berukuran $6 \times 4,5 \mathrm{~cm}$. Sedangkan sudut minimalnya diperoleh $20^{\circ}$ dan sudut maksimalnya adalah $160^{\circ}$.
\end{abstract}

Kata kunci : Augmented Reality, Marker Based Tracking, Rumah adat di Indonesia, sudut, jarak

\section{Pendahuluan}

Di zaman yang serba praktis dewasa ini, banyak manusia yang membutuhkan kemudahan dalam melakukan aktivitasnya. Hal ini yang mendorong sehingga perkembangan teknologi berkembang begitu pesatnya. Sehingga berdampak yang sangat signifikan terhadap banyaknya penemuan-penemuan yang baru. Penggunaan teknologi multimedia dalam sebuah aplikasi sangat dibutuhkan untuk mendapatkan tampilan yang menarik. Salah satu perkembangan teknologinya pada bidang digital imaging yaitu Augmented Reality(AR).

Istilah Augmented Reality ada sejak tahun 1992 yang dikenalkan oleh Caudell dan Mizell(1992) untuk mendeskripsikan penumpukan objek virtual dengan objek virtual yang dihasilkan oleh komputer [1]. Augmented Reality dapat juga didefinisikan pengkombinasian objek digital baik 3 dimensi maupun 2 dimensi dengan objek nyata secara langsung dan memiliki kelebihan yaitu menjadikan tampilan terlihat semakin interaktif dan secara real time [2]. Oleh karena itu Augmented reality pada saat ini sedang banyak digunakan dalam aplikasi untuk menunjang pekerjaan seperti misalnya dalam hal militer, kesehatan, game, arsitektur dan juga dapat diterapkan sebagai alat bantu sehari hari pada bidang pendidikan, pengetahuan, sosial dan lain sebagainya [3]. Dibidang pendidikan salah satunya dapat digunakan sebagai media pembelajaran untuk pengenalan rumah adat yang terdapat di Indonesia. Dengan menggunakan teknologi ini, seseorang akan mendapat sensasi berbeda dalam belajar.

Pada penelitian membahas tentang Penggunaan Augmented Reality dengan metode Marker Based Tracking sebagai media pengenalan Rumah adat yang ada di indonesia yang ditujukan sebagai media pembelajaran anak pada usia sekolah dasar sampai dengan usia sekolah menengah pertama.

Augmented Reality dengan metode tracking terbagi menjadi dua jenis, yang pertama marker based tracking dan yang kedua markerless. Metode tracking ini memiliki persamaan dalam mendeteksi ataupun memunculkan objek virtualnya [4]. Penelitian ini diharapkan dapat memperoleh jarak pendeteksian yang tepat dan optimal dalam memunculkan objek virtual pada Augmented Reality. 


\section{Metode Penelitian}

\section{A. Augmented Reality}

Augmented Reality merupakan bagian dari Virtual Environment atau biasa dikenal sebagai Virtual Reality[5]. Augmented Reality yaitu salah satu media penghubung antara manusia dengan komputer dengan cara menambahkan objek virtual kedalam lingkungan yang nyata yang dibuat oleh komputer sehingga seakan akan tidak ada batasnya karena batas yang ada sangat tipis[2][6]

\section{B. Marker Based Tracking}

Marker Based Tracking merupakan salah satu metode dalam augmented reality yang memerlukan penanda ataupun marker berupa gambar atau objek 2 dimensi untuk dapat memunculkan maupun menampilkan objek virtualnya[2][4]

\section{Vuforia SDK}

Vuforia adalah Augmented Reality (AR) Software Development Kit (SDK) untuk pengembangan aplikasi Augmented Reality pada perangkat mobile. Awalnya Vuforia lebih dikenal dengan Qualcom Company Augmented Reality (QCAR). Dengan teknologi Computer Vision, sehingga vuforia dapat melakukan pengenalan dan pelacakan gambar yang menjadi target pada objek sederhana secara real time[7]

\section{Unity 3D}

Unity 3D atau yang lebih dikenal dengan unity merupakan game engine dan juga Integrated Development Environment (IDE) yang digunakan untuk membuat games ataupun media interaktif. Unity ini merupakan game engine yang termasuk gratis. Namun pada hal tertentu unity dikenakan biaya

\section{E. Kamera}

Dalam pendeteksian marker, membutuhkan sebuah kamera untuk mencari titik dimana objek virtual yang telah ditentukan dapat tampil pada layar. Sehingga kamera dapat disebut sebagai alat untuk memindai ataupun membaca marker.

Penelitian ini bertujuan untuk meneliti pemanfaatan metode marker based tracking (image target) dengan Vuforia SDK. Fokus pada penelitian ini adalah pengaruh sudut kemiringan dan juga jarak pendeteksian dalam marker pada Augmented Reality untuk memunculkan objek virtual terhadap metode tracking tersebut.
Berikut merupakan rancangan untuk pengujian yang akan dilakukan tersaji dalam Gambar 1,

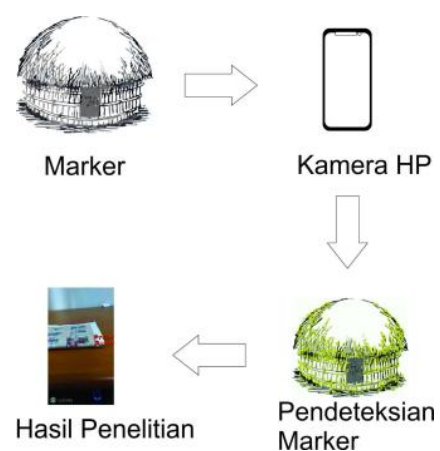

Gambar 1. Alur kerja sistem Marker Based Tracking

Dari Gambar 1 diatas diketahui bahwa pertama-tama marker yang telah dibuat akan dipindai oleh kamera smartphone melalui aplikasi yang telah dibuat. Setelah marker berhasil terbaca dan terdeteksi maka akan dihasilkan tampilan visual.

Pengambilan data penelitian menggunakan metode percobaan uji aplikasi. Percobaan untuk memperoleh hasil pengujian yang berdasarkan parameter yang telah ditentukan yaitu sudut kemiringan dan jarak pendeteksian.

1) Teknik Pengujian

Tahapan teknik pengujian adalah sebagai berikut:

a. Menentukan kebutuhan pengujian.

b. Membangun perangkat lunak aplikasi augmented reality dengan spesifikasi perangkat keras ditentukan.

c. Melakukan instalasi aplikasi pada perangkat gawai (smartphone).

d. Pengujian dan pengambilan data percobaan sesuai dengan indikator variabel yang ada yaitu sudut kemiringan dan jarak pendeteksian, dengan ketentuan, yaitu:

- Pengujian setiap sudut kemiringan dilakukan pada setiap jarak pendeteksian.

e. Melakukan analisis data hasil pengujian.

f. Merumuskan kesimpulan dari penelitian.

2) Indikator Variabel

Pada penelitian ini, akan dilakukan analisis terhadap pengaruh sudut kemiringan serta jarak antara objek dengan gawai yang digunakan untuk melakukan pengujian terhadap pendeteksian marker. Adapun indikator variable, sub indikator, dan skala 
pengukuran dapat dilihat pada Tabel 1 dan Tabel 2 dibawah ini.

Tabel 1. Indikator Variabel Sudut

(Diasumsikan dengan skala pengukuran derajat)

\begin{tabular}{|l|l|}
\hline \multicolumn{2}{|c|}{ Indikator Variabel Sudut Kemiringan } \\
\hline No. & Indikator Sub Variabel \\
\hline 1. & Pendeteksian pada sudut 10 derajat \\
\hline 2. & Pendeteksian pada sudut 20 derajat \\
\hline 3. & Pendeteksian pada sudut 30 derajat \\
\hline 4. & Pendeteksian pada sudut 45 derajat \\
\hline 5. & Pendeteksian pada sudut 60 derajat \\
\hline 6. & Pendeteksian pada sudut 90 derajat \\
\hline 7. & Pendeteksian pada sudut 100 derajat \\
\hline 8. & Pendeteksian pada sudut 110 derajat \\
\hline 9. & Pendeteksian pada sudut 120 derajat \\
\hline 10. & Pendeteksian pada sudut 135 derajat \\
\hline 11. & Pendeteksian pada sudut 160 derajat \\
\hline 12. & Pendeteksian pada sudut 170 derajat \\
\hline & Tabel 2. Indikator Variabel Jarak \\
\hline Diasumsikan dengan skala pengukuran cm) \\
\hline \multicolumn{3}{|l|}{ Indikator Variabel Jarak } \\
\hline No. & Indikator Sub Variabel \\
\hline 1. & Pendeteksian pada jarak $6 \mathrm{~cm}$ \\
\hline 2. & Pendeteksian pada jarak $12 \mathrm{~cm}$ \\
\hline 3. & Pendeteksian pada jarak $18 \mathrm{~cm}$ \\
\hline 4. & Pendeteksian pada jarak $25 \mathrm{~cm}$ \\
\hline 5. & Pendeteksian pada jarak $35 \mathrm{~cm}$ \\
\hline 6. & Pendeteksian pada jarak $45 \mathrm{~cm}$ \\
\hline 7. & Pendeteksian pada jarak $55 \mathrm{~cm}$ \\
\hline 8. & Pendeteksian pada jarak $65 \mathrm{~cm}$ \\
\hline 9. & Pendeteksian pada jarak $75 \mathrm{~cm}$ \\
\hline 10. & Pendeteksian pada jarak $85 \mathrm{~cm}$ \\
\hline 11. & Pendeteksian pada jarak $95 \mathrm{~cm}$ \\
\hline 12. & Pendeteksian pada jarak $100 \mathrm{~cm}$ \\
\hline & \\
\hline
\end{tabular}

\section{Hasil dan Pembahasan}

\section{A. Alat dan Bahan Pengujian}

Pengujian marker based tracking menggunak vuforia SDK memerlukan beberapa peralatan dengan spesifikasi tertentu, Diantaranya.

1) Smartphone

\begin{tabular}{|l|l|}
\hline Tipe & Smartphone Phablet \\
\hline OS & $\begin{array}{l}\text { Android (miui8 based on } \\
\text { android) }\end{array}$ \\
\hline Processor & $\begin{array}{l}\text { Qualcomm Snapdragon } \\
625 \text { Octa Core Processor }\end{array}$ \\
\hline Kecepatan CPU & $2 \mathrm{GHz}$ \\
\hline RAM & $3 \mathrm{~GB}$ \\
\hline Storage & $32 \mathrm{~GB}$ ROM \\
\hline Baterai & $4100 \mathrm{mAh}$ \\
\hline Kamera Utama & $\begin{array}{l}13 \mathrm{MP} \text { with Auto Focus, } \\
\text { flashlight }\end{array}$ \\
\hline Kamera Depan & $5 \mathrm{MP}$ \\
\hline Dimensi & $151 \times 76 \times 8.45 \mathrm{~mm}$ \\
\hline
\end{tabular}

2) Media Pengujian

Berdasarkan dengan perencanaan sebelumnya, pengujian akan dilakukan dengan dua indikator yaitu sudut dan pengaruh jarak pada aplikasi augmented reality.

Berikut ini adalah contoh saat melakukan pengujian.
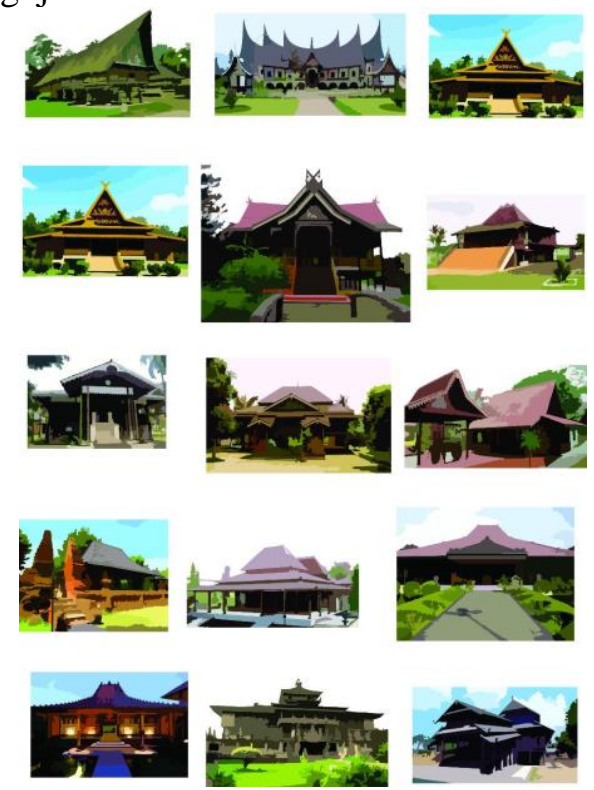

Gambar 2. Media gambar yang digunakan sebagai marker

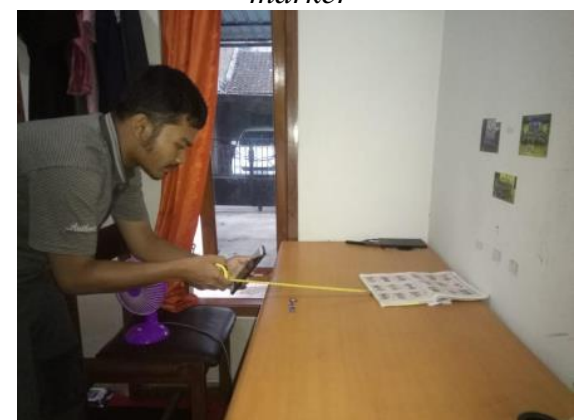

Gambar 3. Melakukan pengujian dengan jarak dan sudut yang telah ditentukan

Adapun spesifikasi dari obyek yang menjadi marker adalah sebagai berikut.

- $\quad$ Ukuran marker $\quad: 6 \mathrm{~cm} \mathrm{x} \mathrm{4,5} \mathrm{cm}$

- Jenis kertas: HVS 100 gr

Sedangkan sumber cahaya yang digunakan adalah.

- Sumber cahaya matahari

- Lampu Fluorescent spiral dengan daya $27 \mathrm{~W}$

Kemudian dalam melakukan pengukuran sudut kemiringan dan juga jarak pendeteksian digunakan alat sebagai berikut.

- Meteran : alat ukur jarak pendeteksian

- Busur digital : alat ukur sudut kemiringan 
Dan berikut ini adalah meteran dan juga busur yang digunakan dalam penelitian ini.

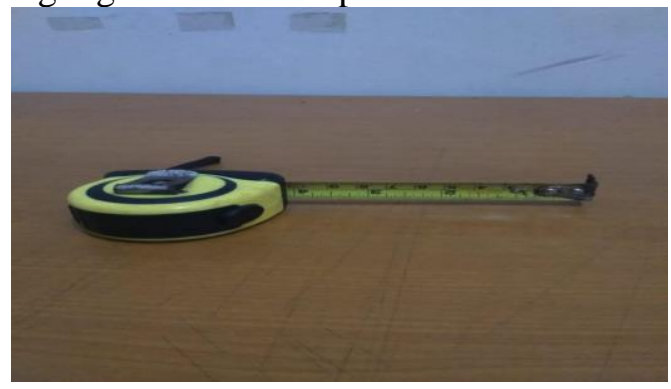

Gambar 4. Alat pengukur derajat sudut dan jarak

\section{B. Hasil Pengujian}

Hasil dari pengujian ini langsung disajikan menjadi 1 (satu) bagian. Pengujian dilakukan di dalam kamar rumah dengan jendela terbuka lebar sebagai akses masuk cahaya matahari dan juga dibantu oleh cahaya lampu. Hasil pengujian dapat dilihat pada tabel 3 .

Kesimpulan yang didapatkan dari Tabel 3 adalah bahwa besar kecilnya derajat kemiringan akan mempengaruhi terbaca atau tidaknya marker, meskipun jarak pendeteksiannya sama.

Tabel 3. Hasil Pengujian Metode Tracking

\begin{tabular}{|c|c|c|c|c|c|c|c|c|c|c|c|c|}
\hline \multirow{2}{*}{ Pengujian Sudut $\left({ }^{\circ}\right)$} & \multicolumn{12}{|c|}{ Pengujian Jarak (cm) } \\
\hline & 6 & 12 & 18 & 25 & 35 & 45 & 55 & 65 & 75 & 85 & & 100 \\
\hline 10 & $x$ & $x$ & $x$ & $\mathrm{x}$ & $x$ & $\mathrm{x}$ & $\mathrm{x}$ & $\mathrm{x}$ & $\mathrm{x}$ & $\mathrm{x}$ & $\mathrm{x}$ & $\mathrm{x}$ \\
\hline 20 & $\mathrm{x}$ & $\mathrm{x}$ & 0 & 0 & 0 & 0 & $\mathrm{x}$ & $\mathrm{x}$ & $\mathrm{x}$ & $\mathrm{x}$ & $\mathrm{x}$ & $\mathrm{x}$ \\
\hline 30 & $x$ & 0 & 0 & 0 & 0 & 0 & 0 & 0 & $\mathrm{x}$ & $\mathrm{x}$ & $x$ & $x$ \\
\hline 45 & 0 & 0 & 0 & 0 & 0 & 0 & 0 & 0 & $\mathrm{x}$ & $x$ & $\mathrm{x}$ & $x$ \\
\hline 60 & 0 & 0 & 0 & 0 & 0 & 0 & 0 & 0 & 0 & $\mathrm{x}$ & $\mathrm{x}$ & $\mathrm{x}$ \\
\hline 90 & 0 & 0 & 0 & 0 & 0 & 0 & 0 & 0 & 0 & 0 & $\mathrm{x}$ & $\mathrm{x}$ \\
\hline 100 & 0 & 0 & 0 & 0 & 0 & 0 & 0 & 0 & 0 & 0 & $x$ & $x$ \\
\hline 110 & 0 & 0 & 0 & 0 & 0 & 0 & 0 & 0 & 0 & $x$ & $x$ & $x$ \\
\hline 120 & 0 & 0 & 0 & 0 & 0 & 0 & 0 & 0 & 0 & $\mathrm{x}$ & $\mathrm{x}$ & $\mathrm{x}$ \\
\hline 135 & 0 & 0 & 0 & 0 & 0 & 0 & 0 & 0 & $x$ & $x$ & $x$ & $x$ \\
\hline 160 & $x$ & $x$ & 0 & 0 & 0 & 0 & $x$ & $x$ & $x$ & $x$ & $x$ & $x$ \\
\hline 170 & $x$ & $x$ & $x$ & $x$ & $x$ & $x$ & $x$ & $x$ & $x$ & $x$ & $x$ & $x$ \\
\hline
\end{tabular}

Dari tabel diatas dapat diketahui bahwa derajat sudut kemiringan yang memiliki jangkauan jarak pendeteksian terjauh adalah sudut $90^{\circ}$ dan juga sudut $100^{\circ}$. Dengan catatan bahwa sudut kemiringan $90^{\circ}$ mempunyai jarak maksimal yaitu $88 \mathrm{~cm}$ sedangkan sudut $100^{\circ}$ memiliki jarak maksimal lebih pendek yaitu $80 \mathrm{~cm}$.

Sedangkan untuk jarak minimalnya, sudut kemiringan $45^{\circ}-135^{\circ}$ mampu untuk membaca marker dari jarak $6 \mathrm{~cm}$. Berikut detail pengujian yang lebih jelas pada Gambar 5 .

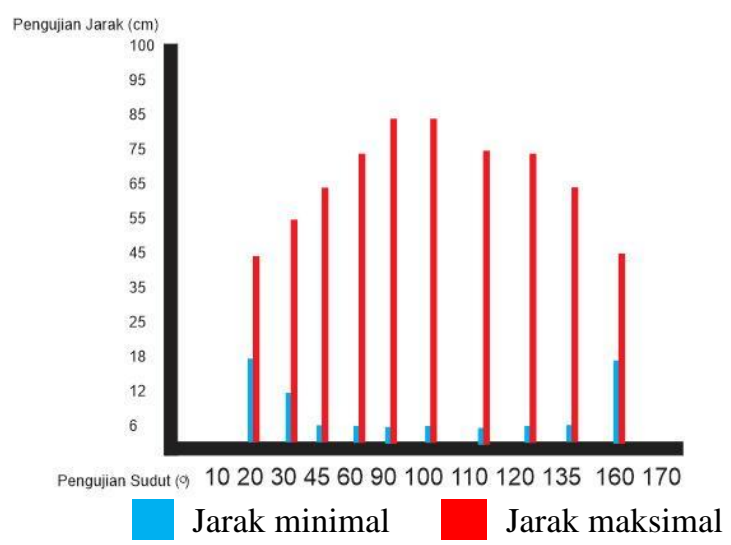

Gambar 5. Hasil Pengujian dalam Gambar Grafik

\section{Kesimpulan}

Dari pengujian yang sudah dilakukan, dapat disimpulkan sebagai berikut:

1. Dilihat dari hasil pengujian yang dilakukan, sudut dan jarak sangatlah berpengaruh dalam pendeteksian marker pada Augmented Reality.

2. Jarak berperan penting dalam pendeteksian marker dengan jarak minimal $6 \mathrm{~cm}$ dan jarak maksimal $85 \mathrm{~cm}$ dengan marker berukuran $6 \times 4,5 \mathrm{~cm}$.

3. Sudut juga sangat mempengaruhi dalam pendeteksian marker dengan sudut minimal $20^{\circ}$ dan sudut maksimal $160^{\circ}$.

Dalam mendeteksi marker pada sudut tertentu, jarak mempengaruhi pendeteksian tersebut. Begitu pula sebaliknya, jarak juga sangat mempengaruhi untuk pendeteksian marker.

\section{Daftar Pustaka}

[1] HÜBNER, P., WEINMANN, M., HILLEMANN, M., JUTZI, B., WURSTHORN, S., 2018. Combining Independent Visualization And Tracking Systems For Augmented Reality

[2] PERWITASARI, I. D. 2018. Teknik Marker Based Tracking Augmented Reality Untuk Visualisasi Anatomi Organ Tubuh Manusia Berbasis Android

[3] SANTOS, C., ARAÚJO, T., MORAIS, J., MEIGUINS, B., 2017. Hybrid Approach Using Sensors, GPS and Vision Based Tracking to Improve the 
Registration in Mobile Augmented Reality Applications

[4] APRIYANI, M.E., HUDA, M., PRASETYANINGSIH, S. 2016. Analisis Penggunaan Marker Tracking pada Augmented Reality Huruf Hijaiyah

[5] HARYANI, P., TRIYONO, J. (2017) Augmented Reality (AR) Sebagai Teknologi Interaktif dalam Pengenalan Benda Cagar Budaya Kepada Masyarakat

[6] KURNIAWAN, D., ARISTOTHELES.,
KURNIAWAN， M.F. 2015. Implementasi Teknologi Markerless Augmented Reality Berbasis Android untuk Mendeteksi dan Mengetahui Lokasi SPBU Terdekat di Kota Bandar Lampung

[7] PONTOAN, G.D., PUTRA, E.Y., 2018. Perancangan Aplikasi Pengenalan Huruf Hiragana dan Katakana Menggunakan Augmented Reality 